\title{
Biochemical and molecular heterogeneity among isolates of Yersinia ruckeri from rainbow trout (Oncorhynchus mykiss, Walbaum) in north west Germany
}

Yidan Huang ${ }^{1}$, Martin Runge ${ }^{2}$, Geovana Brenner Michael ${ }^{3}$, Stefan Schwarz ${ }^{3}$, Arne Jung ${ }^{4}$ and Dieter Steinhagen ${ }^{*}$

\begin{abstract}
Background: Enteric Redmouth Disease (ERM), caused by Yersinia ruckeri, is one of the most important infectious diseases in rainbow trout (Oncorhynchus mykiss) aquaculture in Europe. More recently, non-motile vaccine resistant isolates appear to have evolved and are causing disease problems throughout Europe, including Germany. The aim of this study was to analyse the variation of biochemical and molecular characteristics of $Y$. ruckeri isolates collected in north west Germany as a basis for strain differentiation. The isolates originated mainly from rainbow trout and were characterised by biochemical profiling, $16 \mathrm{~S}$ rDNA sequencing, repetitive sequence-based PCRs, including $(G T G)_{5}{ }^{-}$ PCR, BOX-PCR, ERIC-PCR and REP-PCR, and pulsed-field gel electrophoresis (PFGE).

Results: In total, 83 isolates were characterised, including 48 isolates collected during a field study in north west Germany. All isolates were confirmed as Y. ruckeri by the API 20E system. Five isolates were additionally confirmed as Y. ruckeri by Y. ruckeri-specific PCR and $16 \mathrm{~S}$ rDNA sequencing. Only 17 isolates hydrolyzed Tween 80/20. Sixty-six isolates (79.5\%) were non-motile. Two different patterns were obtained by REP-PCR, five patterns by ERIC-PCR, four patterns by $(\mathrm{GTG})_{5}-\mathrm{PCR}$ and three patterns by BOX-PCR. Notl-directed PFGE resulted in 17 patterns that differed from each other by 25-29 fragments. Isolates from the field study clustered together as PFGE type C. According to the results of API 20E, repetitive sequence-based PCRs and PFGE, these isolates could be subdivided into 27 different groups.
\end{abstract}

Conclusions: The detailed molecular and phenotypic characterisation scheme developed in this study could be used to help trace the dissemination of $Y$. ruckeri isolates, and thus may represent part of improved disease monitoring plans in the future.

Keywords: Enteric Red mouth Disease, REP-PCR, ERIC-PCR, BOX-PCR, PFGE, Non-motile strains

\section{Background}

Enteric Red mouth Disease (ERM), caused by Yersinia ruckeri, is one of the most important infectious diseases in rainbow trout (Oncorhynchus mykiss) aquaculture in Europe. Signs of a clinical infection of rainbow trout may include haemorrhages in various tissues and organs, particularly around the mouth, in the gills, muscles, peritoneum and the lower intestine. The bacterium has

\footnotetext{
* Correspondence: dieter.steinhagen@tiho-hannover.de

${ }^{1}$ Fish Disease Research Unit, University of Veterinary Medicine Hannover, Foundation, Hannover, Germany

Full list of author information is available at the end of the article
}

been isolated from various fish species, including rainbow trout, steelhead (Oncorhynchus mykiss), lake trout (Salvelinus namaycush), cutthroat (O. clarkii), brown (Salmo trutta) and brook trout (S. fontinalis), coho (O. kisutch), sockeye (O. nerka), Chinook (O. tshawytscha) and Atlantic salmon (Salmo salar) [1]. In Europe, it is endemic in many trout farms and can cause high economic losses [2-6]. The disease most commonly affects younger rainbow trout at temperatures above $10^{\circ} \mathrm{C}$. Outbreaks are often related to adverse situations or stressed carrier fish which shed the pathogen and facilitate the onset of an infection. In infected trout populations,

\section{Biomed Central}


ERM can be controlled effectively by antibiotic treatment and by the application of inactivated whole cell vaccines [7], which are available commercially and are considered to be successful [8]. Nevertheless, outbreaks of ERM are still periodically observed, especially in endemic areas.

Among $Y$. ruckeri isolates, several serological variations have been reported [9-11]. While initially most outbreaks of ERM were caused by $Y$. ruckeri isolates of serotype O1 (Hagerman strain), Y. ruckeri isolates of different serotypes have been more recently obtained from sick fish during outbreaks of ERM in the UK, Spain and the U.S.A. [12-14]. Moreover, several of the commercial ERM vaccines seemed to not provide sufficient protection against infections caused by some of these isolates [13,14]. All these 'vaccine-tolerant' isolates lacked motility (assigned as biotype 2, BT2 isolates), while isolates from previous outbreaks were all motile (biotype 1) [13]. It was hypothesised that vaccination resulted in a selective pressure that enabled the emergence of non-motile isolates that are tolerant to the commercial vaccines. Therefore, there is a high risk that these non-motile vaccine-tolerant isolates spread and cause severe outbreaks of disease in trout farms. Wheeler et al. [15] found that the BT2 isolates in mainland Europe have arisen independently from the local BT1 isolates. Recently, Welch et al. [16] indicated that the European BT2 isolates were not from the same clonal group. In Germany, the earliest report about BT2 isolates was published in 1994 [17]. Recently, 'vaccine-tolerant' $Y$. ruckeri were isolated from outbreaks in trout hatcheries in north west Germany, in particular in the federal state of North Rhine-Westphalia (NRW).

In order to avoid further spreading of these 'vaccinetolerant' isolates, an epidemiological survey on the occurrence and further phenotypic and molecular characterisation of $Y$. ruckeri from trout hatcheries was performed. In this study, interspecies differences of $Y$. ruckeri isolates from north west Germany were detected via biochemical and molecular traits to determine how related isolates from different origins are. For this, several typing methods were compared for their ability to differentiate $Y$. ruckeri isolates from rainbow trout and other fish species.

\section{Results}

\section{Biochemical and physiological characterisation}

Among the variable biochemical characteristics of all 83 Y. ruckeri isolates (Table 1), gelatine hydrolysis, VogesProskauer (VP) reaction and Tween hydrolysis were the most variable biochemical reactions. The results of VP, nitrate production, citrate utilization and gelatine hydrolysis from both, conventional biochemical analysis and testing by the API 20E system, were listed also in Table 1. For motility, Tween $80 / 20$ hydrolysis and citrate utilization, the isolates obtained in Lower Saxony (LS) from fish species other than rainbow trout were more similar to the reference strain DSM 18,506 than the isolates obtained from rainbow trout hatcheries in NRW and LS. Only 16 isolates hydrolysed Tween 80/ 20 . For these isolates motility was confirmed by microscopical inspection as well as by cultivation in API M

Table 1 Biochemical characteristics of Yersinia ruckeri isolates from fish in aquaculture in north west Germany

\begin{tabular}{|c|c|c|c|c|c|c|}
\hline \multirow[t]{3}{*}{ Test } & \multirow{3}{*}{$\begin{array}{l}\text { Reference strain } \\
\text { (DSM 18,506) }\end{array}$} & \multicolumn{5}{|c|}{ Number of the field isolates tested positive (\%) } \\
\hline & & Total & $\begin{array}{l}\text { Isolates from } \\
\text { rainbow trouts in } \mathrm{H}\end{array}$ & $\begin{array}{l}\text { Isolates from } \\
\text { rainbow trouts in N }\end{array}$ & $\begin{array}{l}\text { Isolates from } \\
\text { rainbow trouts in L }\end{array}$ & $\begin{array}{l}\text { Isolates from } \\
\text { other fish in } \mathrm{L}\end{array}$ \\
\hline & & $(n=82)$ & $(n=8)$ & $(n=49)$ & $(n=19)$ & $(n=6)$ \\
\hline Motility & + & $16(19.5)$ & $1(12.5)$ & $4(8.2)$ & $6(31.6)$ & $5(83.3)$ \\
\hline Nitrate reduction & + & $77(93.9)$ & $8(100.0)$ & $47(95.9)$ & $17(89.5)$ & $5(83.3)$ \\
\hline Nitrate reduction * & - & $72(87.8)$ & $8(100)$ & $45(91.8)$ & $14(73.7)$ & $5(83.3)$ \\
\hline Citrate utilization & + & $59(72.0)$ & $6(75.0)$ & $32(65.3)$ & $15(78.9)$ & $6(100)$ \\
\hline Citrate utilization * & + & $50(61.7)$ & $6(75.0)$ & $29(59.2)$ & $10(52.6)$ & $5(83.3)$ \\
\hline Voges-Proskauer & - & $48(58.5)$ & $5(62.5)$ & $29(59.2)$ & $10(52.6)$ & $4(66.7)$ \\
\hline Voges-Proskauer* & - & $52(63.4)$ & $4(50.0)$ & $37(75.5)$ & $7(36.8)$ & $4(66.7)$ \\
\hline Gelatine hydrolysis & - & 81 (98.8) & $8(100.0)$ & $49(100.0)$ & $19(100.0)$ & $5(83.3)$ \\
\hline Gelatine hydrolysis* & - & $77(93.9)$ & $8(100.0)$ & $48(98.0)$ & $16(84.2)$ & $5(83.3)$ \\
\hline Methyl-red & + & $76(92.7)$ & $7(87.5)$ & $48(98.0)$ & $18(94.7)$ & $3(50.0)$ \\
\hline Tween 20 hydrolysis & + & $16(19.5)$ & $1(12.5)$ & $4(8.2)$ & $6(31.6)$ & $5(83.3)$ \\
\hline Tween 80 hydrolysis & + & $16(19.5)$ & $1(12.5)$ & $4(8.2)$ & $6(31.6)$ & $5(83.3)$ \\
\hline Acid from sorbitol & - & $5(6.1)$ & $1(12.5)$ & $1(2.0)$ & $0(0.0)$ & $3(50.0)$ \\
\hline
\end{tabular}

* API 20E test system.

L: Lower Saxony, H: Hessen, N: North Rhine-Westphalia. 
medium. Those isolates were recognized as non-motile isolates. In particular, isolates collected from trout hatcheries in NRW were lacking flagella and motility; 92\% of the isolates from this federal state were non-motile (Table 1).

In the API 20E test, 27 isolates showed the numeric profile 5,107,100, 23 isolates with the numeric profile $5,306,100$. These profiles differed from that of the reference strain DSM 18,506 with the profile 5,304,100. For a biochemical typing of the isolates, typing numbers from "a" to " $\mathrm{g}$ " were assigned to individual isolates according to their profile number (Table 2).

\section{Genetic characterisation}

When the isolates were analysed by repetitive sequencebased PCR assays, two amplicon patterns were obtained after REP-PCR, five patterns by ERIC-PCR, four patterns by (GTG) $)_{5}$-PCR and three patterns by BOX-PCR (Figure 1). The similarity rates in REP-PCR were clearly lower than in the other repetitive sequence-based PCRs. In BOX-PCR and (GTG) $)_{5}-\mathrm{PCR}$, the reference strain DSM 18,506 exhibited the same amplicon patterns as most of the isolates (Figure 1). By REP-PCR, 3 or 19 bands were seen in the size range of 200-2000 bp; by BOX-PCR, 18-19 bands were found distributed between $340-1550$ bp; by $(\mathrm{GTG})_{5^{-}}$

Table 2 Different genetic groups of $Y$. ruckeri

\begin{tabular}{|c|c|c|c|c|c|c|c|}
\hline \multicolumn{5}{|c|}{ Patterns from different genotypic method ${ }^{a}$} & \multirow{2}{*}{$\begin{array}{l}\text { API } 20 \mathrm{E} \\
\text { profile }^{b}\end{array}$} & \multirow{2}{*}{$\begin{array}{l}\text { No. of } \\
\text { isolates }\end{array}$} & \multirow{2}{*}{$\begin{array}{l}\text { Typing } \\
\text { Group (tp) }\end{array}$} \\
\hline REP-PCR & BOX-PCR & $(\mathrm{GTG})_{5}-\mathrm{PCR}$ & ERIC-PCR & PFGE & & & \\
\hline \multirow[t]{25}{*}{ R1 } & B1 & G1 & E1 & Pt C1 & a & 5 & tp1 \\
\hline & & & & & $b$ & 21 & tp2 \\
\hline & & & & & c & 1 & tp3 \\
\hline & & & & & $d$ & 1 & tp4 \\
\hline & & & & & h & 2 & tp5 \\
\hline & & & & Pt C10 & a & 8 & tp6 \\
\hline & & & & & $\mathrm{b}$ & 1 & tp7 \\
\hline & & & & & c & 7 & tp8 \\
\hline & & & & & $d$ & 1 & $\operatorname{tp} 9$ \\
\hline & & & & & g & 1 & tp10 \\
\hline & & & & Pt C4 & c & 1 & tp11 \\
\hline & & & & Pt C6 & $g$ & 1 & tp12 \\
\hline & & & & Pt C8 & $b$ & 2 & tp13 \\
\hline & & & & Pt C9 & a & 1 & tp14 \\
\hline & & & & Pt C3 & $b$ & 1 & tp15 \\
\hline & & & & Pt C7 & c & 3 & tp16 \\
\hline & & & & Pt C5 & d & 1 & tp17 \\
\hline & & & & Pt C2 & a & 7 & tp18 \\
\hline & & & & & $b$ & 2 & tp19 \\
\hline & & & & & c & 7 & tp20 \\
\hline & & & & Pt C11 & a & 2 & tp21 \\
\hline & & & & $\mathrm{PtC} 12$ & c & 1 & tp22 \\
\hline & & G 2 & E 3 & Pt A1 & e & 1 & $\operatorname{tp} 23$ \\
\hline & B 2 & G4 & E 4 & Pt A2 & e & 1 & tp24 \\
\hline & B 3 & G3 & E 2 & Pt B1 & $f$ & 1 & tp25 \\
\hline R 2 & B 1 & G1 & E 5 & Pt B2 & e & 2 & tp26 \\
\hline R 3 & B 1 & $\mathrm{G} 1$ & E 6 & Pt D1 & g & $1\left(\right.$ DSM18506) $^{b}$ & tp27 \\
\hline
\end{tabular}

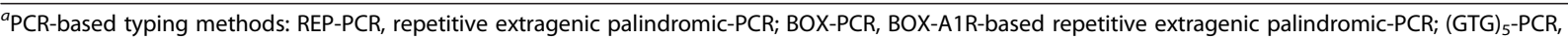
polytrinucleotide $(\mathrm{GTG})_{5}-\mathrm{PCR}$; ERIC-PCR, enterobacterial repetitive intergenic consensus-PCR. Macrorestriction-based typing method, PFGE macrorestriction analyis by pulsed-field gel electrophoresis.

${ }^{b}$ Reference strain DS̄M 18506.

${ }^{C}$ API 20E profiles were as follows: a $(5,306,100, n=23), b(5,107,100, n=27), c(5,307,100, n=20), d(5,106,100, n=3)$, e $(5,307,500, n=4), f(5,305,700, n=1)$, $\mathrm{g}(5,304,100, \mathrm{n}=2+$ reference strain DSM 18,506), h $(5,104,100, \mathrm{n}=2)$. 
A

Dice similarity coefficient (\%) REP pattern Pattern No. of isolates

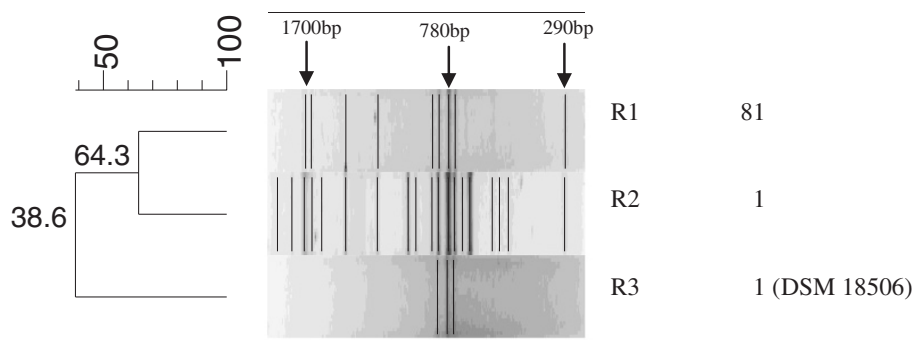

B

Dice similarity coefficient (\%) BOX pattern $\quad$ Pattern No. of isolates

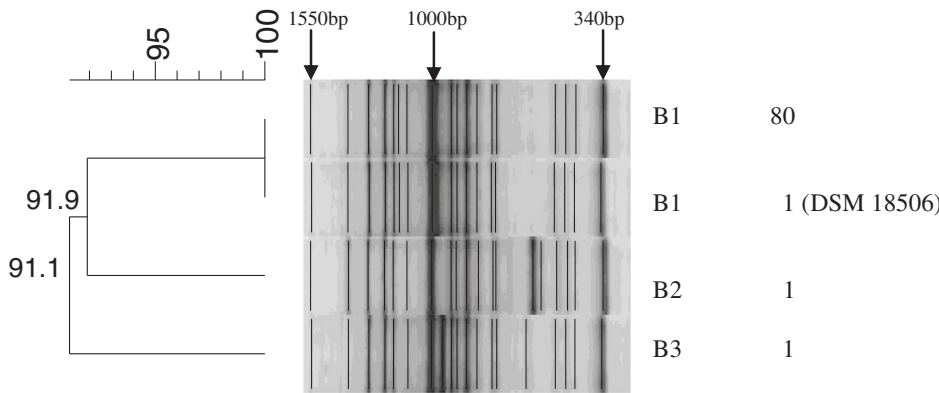

C

Dice similarity coefficient (\%) (GTG)5 pattern Pattern No. of isolates

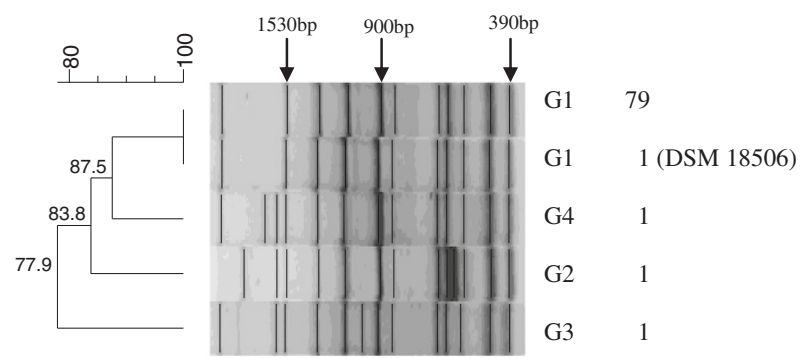

D

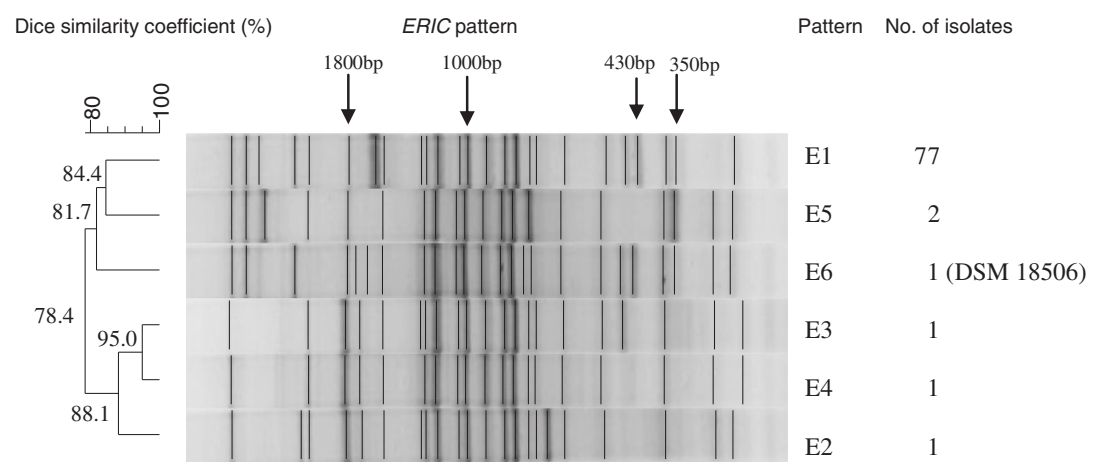

Figure 1 A dendrogram of $Y$. ruckeri isolates constructed using the UPGMA method (tolerance 1\%) using Gel Compar II (Applied Maths), based on fingerprints of different repetitive sequence-based PCRs: A, REP-PCR; B, BOX-PCR; C, (GTG)5-PCR; D, ERIC-PCR. 
PCR, 11-13 bands were detected from 390-2500 bp; and by ERIC-PCR, 20-25 bands were present in the range from 200-2000 bp (Figure 1). Five isolates, which were positive in sorbitol fermentation, did not exhibit the 430 bp amplicon in ERIC-PCR. Only five isolates from fish species other than rainbow trout showed some differences in repetitive PCRs. These five isolates were additionally confirmed as $Y$. ruckeri (identities $=100 \%$, data not shown) by $16 \mathrm{~S}$ rDNA sequencing; while the nucleotide sequence of the reference strain DSM 18,506 was not completely identical to the sequence reported from the strain ATCC 29,473 (identities $=99 \%$, data not shown). Conversely, all the isolates from rainbow trout showed rather uniform patterns of repetitive sequence-based PCR.

NotI-directed PFGE yielded four major PFGE groups A-D. A total of 17 different PFGE types (A1, A2, B1, B2, C1-C12, D) were detected among the 83 Y. ruckeri isolates examined (Figure 2, Table 2). Cluster analysis of these PFGE types showed that the isolates from north west Germany were highly uniform, whereby 30 isolates (36.1\%) belonged to PFGE type $\mathrm{C} 1$ and 18 isolates to PFGE type C10 (Figure 2). Compared with the reference strain DSM 18,506, all the isolates were different. The isolates from rainbow trout were clustered together (PFGE group C). Isolates from pike, koi and brown trout (PFGE groups $\mathrm{A}$ and $\mathrm{B}$ ) showed the greatest variation when compared to rainbow trout isolates. All isolates previously assigned to biotype 2 clustered in PFGE group C. Isolates from this PFGE group were found in the federal states of
LS, Hessen $(\mathrm{H})$ and NRW (Figure 2). Most of the isolates were distributed in all three federal states (PFGE type C1 and $\mathrm{C} 10$ ), while isolates of PFGE type C2 were found only in LS and NRW (Figure 2).

\section{Discriminatory indices of the typing methods applied}

As a discriminatory index, Simpson's index of diversity was calculated for each typing method used to differentiate all $Y$. ruckeri isolates. Discriminatory indices varied distinctly between the different typing methods. REPPCR had the lowest D value of 0.048 . This means that two randomly selected isolates of this test population had a probability of $4.8 \%$ of showing a different REP-PCR pattern. Slightly higher $D$ values were calculated for BOXPCR $(D=0.071)$, (GTG)5-PCR $(D=0.095)$ and ERIC-PCR $(D=0.140)$. Highest $\mathrm{D}$ values were seen for biotyping via API 20E $(D=0.763)$ and NotI-directed PFGE $(D=0790)$. According to their biochemical and molecular characteristics as obtained by testing with API 20E, PFGE and various PCR-based methods, the Y. ruckeri isolates from north west Germany could be subdivided into 27 different groups (Table 2). Most of the isolates from north west Germany (30, 36.6\%) belonged to the group (R1/B1/G1/E1/PFGE type $\mathrm{C} 1$ ). Additional information about the origins and isolated years were shown in Additional file 1: Table S1.

\section{Discussion}

Since the first isolation of $Y$. ruckeri in Idaho, USA in 1950s, outbreaks of ERM were frequently reported 
$[7,18,19]$, especially from the aquaculture industry in countries such as Croatia [3], France [4,20], Finland [2], Germany [5], Italy [21], Switzerland [6] and the UK $[14,22]$. The bacterium was isolated from different host species $[2,23,24]$, including several salmonid species, channel catfish, goldfish, common carp, European eel, coalfish, and perch. Typing of $Y$. ruckeri isolates from various geographic locations or different fish species has been performed for taxonomic or epidemiological purposes and initially it was based on phenotypical characteristics including the results of biochemical and serological tests $[10,25,26]$. In addition, molecular techniques, including random amplification of polymorphic DNA (RAPD), multilocus sequence typing (MLST) or pulsed-field gel electrophoresis (PFGE) have been applied to study the genetic diversity of $Y$. ruckeri isolates [15,27-29]. In a study on isolates from various geographic origins, including Chile, Peru, U.S.A., UK, and mainland Europe, a considerable intraspecies diversity of $Y$. ruckeri was found on the basis of the phenotypical characteristics obtained from API 20E, lipopolysaccharide (LPS) and outer membrane profiles [30] as well as by genetic analysis using MLST profiles [27].

The isolates from north west Germany investigated in the present study, showed a strong homogeneity of biochemical results and API 20E profiles with some variability in gelatine hydrolysis, VP reaction and Tween hydrolysis. Variation in some biochemical tests for $Y$. ruckeri has been reported in previous studies $[27,30,31]$, but this variation could not be used as a distinguishing characteristic for phenotypical traits such as serotype or biotype [25,30,32]. While the majority of $Y$. ruckeri isolates from farmed rainbow trout in Peru [33] or Atlantic salmon in Chile [34] were motile, only 16 out of 82 isolates from the present study belonged to biotype 1 (motile and lipase positive). All other isolates could not hydrolyse Tween $80 / 20$, were lipase-negative and lacked flagella.

The API 20E profiles 5,306,100, 5,107,100, 5,104,100 were previously obtained from $Y$. ruckeri isolates from southwest Germany [35], the profiles 5,307,100 and 5,304,100 were already reported from Spanish isolates [13]. While the profiles 5,106,100 and 5,307,500 were also previously reported from Y. ruckeri isolates, [36] there was no record about an isolate with the numeric profile 5,305,700. However, 16S rRNA sequencing confirmed this isolate as Y. ruckeri (identity $=100 \%$, data not shown).

In addition to the biochemical characteristics, some genetic variability was observed in isolates using several repetitive sequence-based PCR techniques including BOX-PCR, ERIC-PCR, (GTG) $)_{5}$-PCR, REP-PCR as well as pulsed-field gel electrophoresis. An analysis of the isolates from north west Germany by repetitive sequence based PCRs gave 3 to 6 groups, with the majority of isolates in one group. Similar observations were already reported from Latin American isolates [33,34]. ERIC-PCR showed the highest discriminatory power. While in previous studies both ERIC-PCR and REP-PCR were considered of some value as tools to study ERM epidemiology [34], in our study, REP-PCR showed the lowest discriminatory power and could not differentiate the isolates very clearly. This could depend on the different origin of the isolates: our isolates originated mainly from rainbow trout, while Bastardo et al. [34] studied isolates from Atlantic salmon. When Y. ruckeri isolates from Peruvian rainbow trout were analysed by REP-PCR, more homogeneous amplicon patterns were observed as well [33].

PFGE has been frequently applied for detailed molecular typing of different bacteria [37-39], as well as for a differentiation among isolates of Y. ruckeri [15]. In the present study, the typing results by PFGE showed strong homogeneity among the isolates obtained from farmed fish species in north west Germany. More than half of the $Y$. ruckeri isolates belonged to the two PFGE types $\mathrm{C} 1$ and $\mathrm{C} 10$, with $36.1 \%$ of the isolates sharing the same PFGE type C1. These two PFGE types belong to the group C PFGE cluster, which comprises isolates from rainbow trout and represents the majority of the isolates. The isolates showing PFGE types A1/A2 or B1/B2 also differed from the other isolates in at least some of their repetitive sequences-based PCR patterns (Table 2). In the present study, no distinct differences were observed in PFGE types from biotype 1 and biotype 2 isolates from rainbow trout.

The data presented in this study may suggest that the isolates from north west Germany originated from the same ancestor and could indicate a clonal population structure. In a previous study on the genetic diversity of $Y$. ruckeri isolates, analysed by MLST, a large number of isolates also belonged to just two sequence types (ST), which formed one clonal complex with 21 out of 30 recognised STs [27]. However, the MLST analysis revealed that genetic recombination appeared to play a greater role than mutation for the generation and maintenance of genetic diversity within the population of $Y$. ruckeri [27]. This would be contradictory to the concept of clonal expansion of a population from a common ancestor that diversified mainly by mutation rather than recombination [40]. MLST results from Y. ruckeri rather suggest an epidemic population structure, as it was observed for instance for Vibrio parahaemolyticus [27,41]. The epidemiology of Yersinia ruckeri, which started as a geographically isolated disease and quickly became disseminated [31], also was considered to support the epidemic model [27].

Pulsed-field gel electrophoretic analysis of $Y$. ruckeri isolates resulted in a discriminatory index $(D)$ of 0.790 , whereas repetitive sequence-based PCR approaches yielded low $D$ values between 0.048 and 0.140 . As the $D$ value describes the probability that two randomly selected isolates 
show different profiles by the method applied, methods with low $D$ values are considered not to be sufficiently discriminative for the detection of differences among $Y$. ruckeri isolates. In a previous analysis, "medium to high" $D$ values ranging between $0.71-0.74$ were obtained by the API 20E, lipopolysaccharide and outer membrane protein analysis [27], while ERIC-and REP-PCR were valuable in combination with other techniques. Similar results were reported from Y. ruckeri isolated in Turkey [42]. The combination of several typing methods, as performed by Bastardo et al. [27] showed that isolates with similar characteristics were associated with certain fish species and/or predominated in some geographical areas. In the present study, the combination of six typing methods, including API 20E, PFGE and four different repetitive sequence PCR techniques facilitated the identification of 27 different groups. With this set of methods, most of the isolates from rainbow trout (97.3\%) could be differentiated from the isolates obtained from pike, koi and brown trout. Biotype 2 isolates were only detected in rainbow trout in this study. The genomic variation of $Y$. ruckeri isolates provides information for comparing their distribution and the relationships among individual isolates from different regions in north west Germany.

\section{Conclusions}

Most of the isolates from north west Germany belonged to biotype 2. The combination of different typing methods could well differentiate $Y$. ruckeri isolates. The results of this study showed the diversity of isolates present in north west Germany. Moreover, these data enable the identification and in-depth characterisation of pathogenic $Y$. ruckeri isolates. As a consequence of this detailed characterisation, these data can be used to examine the distribution of these isolates in the field and may be used as a basis for preventive disease monitoring plans.

\section{Methods}

\section{Bacterial isolates and sample collection}

In total, 83 Yersina ruckeri isolates were analysed, including 33 isolates from the strain collection of LAVES Niedersachsen, Food and Veterinary Institute Braunschweig/Hannover, Germany and the fish disease service at the Landesbetrieb Hessisches Landeslabor (LHL) Giessen, Germany. These bacteria were isolated from diseased rainbow trout suffering from ERM outbreaks. In addition, 48 isolates were sampled from rainbow trout (Oncorhynchus mykiss) in trout hatcheries at different sites in the German federal state NRW during the four seasons of 2011-2012. Sampling was done under the approval of Landesamt für Natur, Umwelt und Verbraucherschutz, NRW. Fish were randomly sampled when diseased fish were not present in the farm. The sampling was done following the guidelines for the diagnostic of fish diseases and regarded international and national guidelines for animal welfare. Of the remaining two isolates, one was the $Y$. ruckeri reference strain DSM 18,506 and the other a non-motile isolate also from NRW in 2008 and provided by Dr. Gould from MSD Animal Heath. All isolates were kept as glycerol stock cultures at $-80^{\circ} \mathrm{C}$. All isolates were cultured on trypticase soy agar (TSA; Sigma) at $25^{\circ} \mathrm{C}$ for $24-48 \mathrm{~h}$ and pure cultures were kept at $-80^{\circ} \mathrm{C}$ using Cryobank beads (Copan Diagnostic INC., USA).

\section{Identification of $Y$. ruckeri}

All Y. ruckeri-suspect cultures were examined by Gramstaining and colony morphology. For species confirmation, the pure-cultured colonies were biochemically characterised by the API $20 \mathrm{E}$ system at $25^{\circ} \mathrm{C}$ for $48 \mathrm{~h}$ (bioMérieux, Craponne, France), as well as subjected to the following standard biochemical tests: cytochromeoxidase production, catalase production, Methylred/VogesProskauer (VP), growth on McConkey agar, xylose utilisation, glucose utilisation/gas production, tween 80/20 hydrolysis, nitrate production, citrate utilisation, sorbitol fermentation, gelatine hydrolysis, and oxidative/ fermentative glucose utilisation. Motility was checked by phase-contrast microscopy $(1000 \times)$. To confirm the motility, bacteria were stab-inoculated with a needle into the bottom of API M medium (bioMérieux). In addition, silver staining [43] was used to investigate the isolates for the presence of flagella. After staining, the slides were microscopically inspected (Leica DFC320, Bensheim, Germany).

\section{DNA extraction}

Bacterial cells were lysed and genomic DNA was extracted, following the manufacturers protocol provided in the innuPREP Bacteria DNA Kit (Analytik Jena, Jena, Germany). The purity of DNA was confirmed using a Nano Drop spectrophotometer (NanoDrop, Delaware, USA).

\section{Repetitive sequence-based PCR approaches}

For genotyping, four different repetitive sequence-based PCRs were performed including BOX-A1R-based repetitive extragenic palindromic-PCR (BOX-PCR), (GTG) $)_{5}$-PCR,

\section{Table 3 Primers used in this study}

\begin{tabular}{llll}
\hline PCR & Name & Sequence $\left(\mathbf{5}^{\prime} \rightarrow \mathbf{3}^{\prime}\right)$ & References \\
\hline Specific PCR & YER8 & GCGAGGAGGAAGGTAAGTG & {$[45]$} \\
of Y. ruckeri & YER10 & GAAGGCACCAAGGCATCTCTG & {$[45]$} \\
$(\text { GTG })_{5}$-PCR & $(\text { GTG })_{5}$ & GTGGTGGTGGTGGT & {$[44]$} \\
BOX-PCR & BOXA1R & CTACGGCAAGGCGACGCTGACG & {$[44]$} \\
ERIC-PCR & ERIC2 & AAGTAAGTGACTGGGGTGAGCG & {$[44]$} \\
& ERIC1R & ATGTAAGCTCCTGGGGATCAC & {$[44]$} \\
REP-PCR & REP2-I & ICGICTTATCIGGCCTAC & {$[44]$} \\
& REP1R-I & IIIICGICGICATCIGGC & {$[44]$} \\
\hline
\end{tabular}


enterobacterial repetitive intergenic consensus (ERIC-PCR) and repetitive extragenic palindromic (REP-PCR). These PCR assays were performed for all Y. ruckeri isolates [44], using primers listed in Table 3. PCRs were performed in $25 \mu \mathrm{l}$ volumes containing $2 \mu \mathrm{l}$ of DNA template, $0.2 \mathrm{mM}$ concentrations of deoxynucleoside triphosphates, $2.5 \mu \mathrm{l}$ of $10 \times$ PCR buffer (Qiagen, Hilden, Germany), $2 \mathrm{mM} \mathrm{MgCl}_{2}$, $8 \mu \mathrm{M}, 1 \mu \mathrm{M}$ and $2 \mu \mathrm{M}$ of each forward and reverse primer for BOX-/(GTG) $)_{5^{-}}$, ERIC-and REP-PCR, respectively, and $5 \mathrm{U}$ of Qiagen HotstarTaq DNA Polymerase (Qiagen). The reaction was performed in a Biometra T3000 thermocycler (Analytik Jena, Germany) with an initial denaturation cycle at $95^{\circ} \mathrm{C}$ for $7 \mathrm{~min}$, followed by 30 cycles of amplification (denaturation for $1 \mathrm{~min}$ at $94^{\circ} \mathrm{C}$, annealing for $1 \mathrm{~min}$ at $53^{\circ} \mathrm{C}, 52^{\circ} \mathrm{C}$ and $44^{\circ} \mathrm{C}$ for BOX, ERIC/(GTG) $)_{5}$, and REPPCR, respectively, and extension for $8 \mathrm{~min}$ at $65^{\circ} \mathrm{C}$ ), and a final elongation for $16 \mathrm{~min}$ at $65^{\circ} \mathrm{C}$. The PCR products were detected by electrophoresis by using $2.5 \%$ agarose gels. The images obtained were analysed by the UPGMA method using GelCompar II (Applied Maths, Belgium).

\section{S rDNA gene sequencing}

A specific PCR for the identification of $Y$. ruckeri was applied to five isolates which showed patterns different from most of the isolates in repetitive sequence-based PCR. For this PCR, the primers YER8 and YER10 (listed in Table 3) were used according to Gibello et al. [45]. The PCR was performed using the Titanium Taq PCR Kit according to the manufacturer's protocol (Clontech, Saint-Germain-en-Laye, France). Briefly, the PCR was performed in $20 \mu \mathrm{l}$ volumes containing $1 \mu \mathrm{l}$ of DNA template, $0.2 \mathrm{mM}$ deoxynucleoside triphosphates, $2 \mu \mathrm{l}$ of $10 \times$ Titanium Taq buffer (Clontech, USA), $10 \mu \mathrm{M}$ of each forward and reverse primer, and $0.1 \mu \mathrm{l}$ of $50 \times$ Titanium Taq DNA Polymerase (Clontech). The reaction was performed in a BIORON thermocycler (BIORON, Germany) with an initial denaturation cycle for $3 \mathrm{~min}$ at $95^{\circ} \mathrm{C}$, followed by 40 cycles of amplification (denaturation for $30 \mathrm{~s}$ at $95^{\circ} \mathrm{C}$, annealing for $30 \mathrm{~s}$ at $60^{\circ} \mathrm{C}$, and extension for $1 \mathrm{~min}$ at $72^{\circ} \mathrm{C}$ ), and a final elongation for $7 \mathrm{~min}$ at $72^{\circ} \mathrm{C}$. PCR products were sent to LGC Genomics (Berlin, Germany) for sequencing. The resulting $16 \mathrm{~S}$ rDNA sequences were compared in a BLAST search with the sequences previously deposited in the NCBI database (www.ncbi.nlm.nih.gov).

\section{Pulsed-field gel electrophoresis (PFGE)}

Isolates to be examined by pulsed-field gel electrophoresis were grown on TSA plates for $48 \mathrm{~h}$ at $25^{\circ} \mathrm{C}$. Agarose plugs containing Yersinia ruckeri genomic DNA were prepared according to the method of Wagley at el [39]. Slices of the agarose plugs that contain $Y$. ruckeri genomic DNA were digested with the restriction endonuclease NotI (100 U) for $4 \mathrm{~h}$ at $37^{\circ} \mathrm{C}$. A Salmonella Braenderup H9812 molecular standard was prepared by the same method and restricted with $\mathrm{XbaI}$ [46]. NotI digested agarose plugs were loaded into a $1 \%(\mathrm{w} / \mathrm{v})$ PFGE-grade agarose gel (Roth, Germany) and subjected to electrophoresis in $0.5 \times$ TBE buffer using a Bio-Rad CHEF-DRIII system. PFGE conditions were $5.6 \mathrm{~V} / \mathrm{cm}$ with switch times of 1 to $15 \mathrm{~s}$ at $14^{\circ} \mathrm{C}$ for $20 \mathrm{~h}$. Images were captured under ultraviolet light. The images obtained were analysed by the UPGMA method using GelCompar II (Applied Maths).

\section{Discriminatory power of typing methods}

Simpson's index of diversity was applied to calculate the discriminatory power of the different typing methods: API 20E, REP-PCR, BOX-PCR, (GTG) 5 -PCR, ERIC-PCR and PFGE according to Hunter and Gaston [47].

\section{Additional file}

Additional file 1: Table S1. Different origins of Yersinia ruckeri.

Competing interests

The authors declare that they have no competing interests.

\section{Authors' contributions}

YH, MR, SS and DS designed the study. YH carried out the biochemical identification and repetitive sequence-based PCRs according to the suggestions from MR and AJ. GBM and YH performed the PFGE and analysed the results under the supervision of SS and DS. YH drafted the manuscript and all authors critically revised the manuscript. All authors read and approved the final manuscript.

\section{Acknowledgements}

We thank Dr. S. Braune (LAVES, Hannover), Dr. C. Gould (MSD Animal Health) and Dr. A. Nilz (LHL Hessen) for the generous provision of isolates that were used in this study. Dr. W. Schäfer and D. Mock (LANUV, Albaum) gave

support during the field sampling, and R. Becker (FLI, Mariensee) provided valuable technical assistance. This work was supported by Landesamt für Natur, Umwelt und Verbraucherschutz Nordrhein-Westfalen (LANUV).

\section{Author details}

${ }^{1}$ Fish Disease Research Unit, University of Veterinary Medicine Hannover, Foundation, Hannover, Germany. ${ }^{2}$ Lower Saxony State Office for Consumer Protection and Food Safety (LAVES), Food and Veterinary Institute Braunschweig/Hannover, Hannover, Germany. ${ }^{3}$ Institute of Farm Animal Genetics, Friedrich-Loeffler-Institute (FLI), Neustadt-Mariensee, Germany. ${ }^{4}$ Clinic for Poultry, University of Veterinary Medicine Hannover, Foundation, Hannover, Germany.

Received: 9 July 2013 Accepted: 16 October 2013 Published: 21 October 2013

\section{References}

1. Noga EJ: Fish disease: diagnosis and treatment. 2nd edition. lowa: WileyBlackwell; 2010.

2. Valtonen ET, Rintamaki P, Koskivaara M: Occurrence and pathogenicity of Yersinia ruckeri at fish farms in northern and central Finland. J Fish Dis 1992, 15:163-171.

3. Oraić D, Zrnčić S, Šoštarić B, Bažulić D, Lipej Z: Occurrence of enteric redmouth disease in rainbow trout(Oncorhynchus Mykiss) on farms in Croatia. Acta Vet Hung 2002, 50(3):283-291.

4. Lesel $\mathrm{R}$, Lesel M: Outbreak of enteric redmouth disease in rainbow trout, Salmo gairdneri Richardson, in France. J Fish Dis 1983, 6:385-387.

5. Fuhrmann $\mathrm{H}$, Boehm KH: An outbreak of enteric redmouth disease in West Germany. J Fish Dis 1983, 6:309-311.

6. Meier W: Enteric redmouth disease: outbreak in rainbow trout in Switzerland. Dis Aquat Organ 1986, 2:81-82. 
7. Ross AJ, Rucker RR, Ewing WH: Description of a bacterium associated with redmouth disease of rainbow trout (Salmo Gairdneri). Can J Microbiol 1966, 12(4):763-770.

8. Tebbit GL, Erickson JD, Vande Water RB: Development and use of Yersinia ruckeri bacterins to control enteric redmouth disease. In International symposium on fish biologies: serodiagnostics and vaccines. vol. 49 : Developments in biological standardization; 1981:395-401.

9. Davies RL: O-Serotyping of Yersinia ruckeri with special emphasis on European isolates. Vet Microbiol 1990, 22:299-307.

10. Davies RL: Clonal analysis of Yersinia ruckeri based on biotypes, serotypes and outer membrane protein-types. J Fish Dis 1991, 14:221-228.

11. Romalde JL, Margarinos B, Barja JL, Toranzo AE: Antigenic and molecular characterization of Yersinia ruckeri: proposal for a new intraspecies classification. Syst Appl Microbiol 1993, 16:411-419.

12. Arias CR, Olivares-Fuster O, Hayden K, Shoemaker CA, Grizzle JM, Klesius PH: First report of Yersinia ruckeri biotype 2 in the USA. J Aquat Anim Health 2007, 19:35-40.

13. Fouz B, Zarza C, Amaro C: First description of non-motile Yersinia ruckeri serovar I strains causing disease in rainbow trout, Oncorhynchus mykiss (Walbaum), cultured in Spain. J Fish Dis 2006, 29:339-346.

14. Austin DA, Robertson PAW, Austin B: Recovery of a new biogroup of Yersinia ruckeri from diseased rainbow trout (Oncorhynchus mykiss, Walbaum). Syst Appl Microbiol 2003, 26:127-131.

15. Wheeler RW, Davies RL, Dalsgaard I, Garcia J, Welch TJ, Wagley S, Bateman KS, Verner-Jeffreys DW: Yersinia ruckeri biotype 2 isolates from mainland Europe and the UK represent different clonal groups. Dis Aquat Organ 2009, 84:25-33.

16. Welch TJ, Verner-Jeffreys DW, Dalsgaard I, Wiklund T, Evenhuis JP, Cabrera JAG, Hinshaw JM, Drennan JD, LaPatra SE: Independent emergence of Yersinia ruckeri biotype 2 in th United States and Europe. Appl Environ Microbiol 2011, 77(10):3493-3499.

17. Klein BU, Kleingeld DW, Bohm KH: First isolation of a non-motile/tween 80 negative Yersinia ruckeri strain in Germany. Bull Eur Assoc Fish Pathol 1994, 14(5):165-166.

18. Karatas S, Candan A, Demircan D: Enteric red mouth disease in cultured rainbow trout (Oncorhynchus Mykiss) on the black sea coast of Turkey. Isr J Aquacult-Bamid 2004, 56(3):226-231.

19. Wang KY, Fan FL, Huang XL, Geng Y, Chen DF, Huang JL: Occurrence and treatment of a channel catfish(Ictalurus punctatus(Rafinesque)) disease, caused by Yersinia ruckeri. Sci Fish Farming 2009, 5:50-51.

20. Coquet $L$, Cosette $P$, Quillet $L$, Petit $F$, Junter GA, Jouenne T: Occurrence and phenotypic charaterization of Yersinia ruckeri strains with biofilm forming capacity in a rainbow trout Farm. App/ Environ Microbiol 2002, 68(2):470-475.

21. Busch RA: Enteric redmouth disease(Hagerman strain). Mar Fish Rev 1978 40:42-51.

22. Roberts MS: A report of an epizootic in hatchery-reared rainbow trout, salmo gairdneri Richardson, at an English trout farm, caused by Yersinia ruckeri. J Fish Dis 1983, 6:551-552.

23. Noga EJ: Enteric redmouth disease (ERM, redmouth, yersiniosis, blood spot, yersinia ruckeri infection). Ames: lowa State University Press; 2000

24. Danley ML, Goodwin AE, Killian HS: Epizootics in farm-raised channel catfish, Ictalurus punctatus(Rafinesque), caused by the enteric redmouth bacterium Yersinia ruckeri. J Fish Dis 1999, 22:451-456.

25. Stevenson RMW, Airdrie DE: Serological variation among Yersinia ruckeri strains. J Fish Dis 1984, 7:247-254

26. Davies RL, Frerichs GN: Morphological and biochemical differences among isolates of Yersinia ruckeri obtained from wide geographical areas. J Fish Dis 1989, 12:357-365.

27. Bastardo A, Ravelo C, Romalde JL: Multilocus sequence typing reveals high genetic diversity and epidemic population structure for the fish pathogen Yersinia ruckeri. Environ Microbiol 2012, 14(8):1888-1897.

28. Schill WB, Phelps SR, Pyle SW: Multilocus electrophoretic assessment of the genetic structure and diversity of Yersinia ruckeri. Appl Environ Microbiol 1984, 48(5):975-979.

29. Lucangeli C, Morabito S, Caprioli A, Achene L, Busani L, Mazzolini E, Fabris A, Macri A: Molecular fingerprinting of strains of Yersinia ruckeri serovar 01 and Photobacterium damsela subsp piscicida isolated in Italy. Vet Microbiol 2000, 76(3):273-281.

30. Bastardo A, Ravelo C, Romalde JL: A polyphasic approach to study the intraspecific diversity of Yersinia ruckeri strains isolated from recent outbreaks in salmonid culture. Vet Microbiol 2012, 160(1-2):176-182.
31. Austin B, Austin DA: Bacterial fish pathogens: diseases of farmed and wild fish. Chichester, UK: Praxis Publishing; 2007.

32. Sousa JA, Magarinos B, Eiras JC, Toranzo AE, Romalde JL: Molacular characterization of Portuguese strains of Yersinia ruckeri isolated from fish culture systems. J Fish Dis 2001, 24:151-159.

33. Bastardo A, Sierralta V, Leon J, Ravelo C, Romalde JL: Phenotypical and genetic characterization of Yersinia ruckeri strains isolated from recent outbreaks in farmed rainbow trout Oncorhynchus mykiss (Walbaum) in Peru. Aquaculture 2011, 317:229-232.

34. Bastardo A, Bohle H, Ravelo C, Toranzo AE, Romalde JL: Serological and molecular heterogenetity among Yersinia ruckeri strains isolated from farmed Atlantic salmon Salmo salar in Chile. Dis Aquat Organ 2011, 93:207-214.

35. Wortberg F, Nardy E, Contzen M, Rau J: Identification of Yersinia ruckeri from diseased salmonid fish by fourier transform infrared spectroscopy. J Fish Dis 2012, 35:1-10.

36. Furones MD, Rodgers CJ, Munn CB: Yersina ruckeri, the causal agent of enteric redmouth disease(ERM) in fish. Annu Rev of Fish Dis 1993, 3:105-125.

37. Aral $H$, Morita $Y$, Izumi $S$, Katagiri $T$, Kimura $H$ : Molecular typing by pulsedfield gel electrophoresis of Flavobacterium psychrophilum isolates derived from Japanese fish. J Fish Dis 2007, 30:345-355.

38. Soto E, Mauel M, Lawrence M: Improved pulsed-field gel electrophoresis procedure for the analysis of Flavobacterium columnare isolates previously affected by DNA degration. Vet Microbio/ 2008, 128:207-212

39. Wagley S, Koofhethile K, Wing JB, Rangdale R: Comparison of V parahaemolyticus isolated from seafoods and cases of gastrointestinal disease in the UK. Int J Environ Health Res 2008, 18(4):283-293.

40. Smith JM, Smith MH, O'Rourke M, Spratt BG: How clonal are bacteria? Proc Natl Acad Sci U S A 1993, 90(10):4384-4388.

41. Gonzalez-Escalona N, Martinez-Urtaza J, Romero J, Espejo RT, Jaykus LA, DePaola A: Determination of molecular phylogenetics of Vibrio parahaemolyticus strains by multilocus sequence typing. J Bacterio/ 2008, 190(8):2831-2840.

42. Onuk EE, Ciftci A, Findik A, Ciftci G, Altun S, Balta F, Ozer S, Coban AY: Phenotypic and molecular characterization of Yersinia ruckeri isolates from rainbow trout (Oncorhynchus mykiss, Walbaum,1792) in Turkey. Berl Munch Tierarztl Wochenschr 2011, 124:320-328.

43. Blenden DC, Goldberg HS: Silver impregnation stain for Leptospira and flagella. Am Soc Microbiol 1965, 80(3):899-900.

44. Amann S: Untersuchung zur Klassifizierung, identifizierung und differenzierung von Yersinia Arten. Wien: University Wien; 2007

45. Gibello A, Blanco MM, Moreno MA, Cutuli MT, Domenech A, Moniguez L, Fernandez-Garayzabal JF: Development of a PCR assay for detection of Yersinia ruckeri in tissues of inoculated and naturally infected trout. Appl EnvironMicrobiol 1999, 65(1):346-350.

46. Hunter SB, Vauterin P, Lambert-Fair MA, VanDuyne MS: Establishment of a universal size standard strain for use with the PulseNet standardized pulsed-field get electrophoresis protocols: converting the national databases to the new size standard. J Clin Microbiol 2005, 43:1045-1050.

47. Hunter PR, Gaston MA: Numerical index of the discriminatory ability of typing systems: an application of simpson's index of diversity. J Clinical Microbiol 1988, 26(11):2465-2466

doi:10.1186/1746-6148-9-215

Cite this article as: Huang et al:: Biochemical and molecular heterogeneity among isolates of Yersinia ruckeri from rainbow trout (Oncorhynchus mykiss, Walbaum) in north west Germany. BMC Veterinary Research 2013 9:215. 